\title{
O LUGAR DO ESTÁGIO NA FORMAÇÃO DE PROFESSORES EM DUAS PERSPECTIVAS: BRASIL E INGLATERRA*
}

\author{
Menga LÜDKE ${ }^{1,2}$ \\ DAVID SCOTT ${ }^{3}$
}

\begin{abstract}
RESUMO: O estágio supervisionado ocupa lugar central na articulação entre o aspecto teórico e o prático na formação de futuros professores. $\mathrm{O}$ artigo apresenta constataçóes de um estudo sobre esse lugar em duas realidades distintas.
\end{abstract}

Palavras-chave: Formação de professores. Preparação teórica e prática. Estágio supervisionado.

\section{TEACHERS PRACTICAL TRAINING AND ITS CENTRAL PLACE IN THE PROCESS OF TEACHERS EDUCATION UNDER TWO DIFFERENT PERSPECTIVES: BRAZIL AND ENGLAND}

ABSTRACT: This text presents findings from a study about the central role played by the practical training in the process of teachers' education under two different perspectives.

Keywords: Teachers education. Theoretical and practical preparation. Practical training.

\section{LE LIEU DU STAGE DANS LA FORMATION DES ENSEIGNANTS SOUS DEUX PERSPECTIVES: BRÉSIL ET ANGLETERRE}

RESUMÉ: L'article présente des résultats d'une recherche sur le rôle central du stage dans l'articulation entre les aspects théorique et pratique de la formation des enseignants sous deux perspectives differentes.

Mots-clés: Formation des enseignants. Preparation théorique et pratique. Stage.

\footnotetext{
*Artigo resultante do projeto de pesquisa "Teacher training under two perspectives: England and Brazil", desenvolvido no Institute of Education da University College of London, dentro do Programa da Cátedra Anísio Teixeira, financiado pela Coordenação de Aperfeiçoamento de Pessoal do Nível Superior (CAPES), entre os anos 2016-2017.

${ }^{1}$ Pontifícia Universidade Católica do Rio de Janeiro - Rio de Janeiro (RJ), Brasil.

${ }^{2}$ Universidade Católica de Petrópolis - Petrópolis (RJ), Brasil. E-mail: menga@puc-rio.br

${ }^{3}$ Instituto de Educação da University College London - Londres, Reino Unido. E-mail: d.scott@ucl.ac.uk DOI: 10.1590/ES0101-73302018183505
} 


\section{Introdução}

formaçáo de professores se encontra na base de sustentaçáo do edifício
da educação, sede para o desenvolvimento dos jovens cidadáos de uma
sociedade. Na brasileira, em que $90 \%$ deles sáo servidos em sua escolarização básica pelas instituiçôes da rede pública, com suas limitaçóes em termos de recursos em relação às da rede privada, avulta de forma evidente a importância do principal desses recursos, o professor e em decorrência sua formação. A grande discussão em torno do papel dos diferentes componentes do processo educativo, com a entrada indiscutível dos recursos tecnológicos, não obscurece a importância, também indiscutível, do papel do professor. Sobretudo na realidade do Brasil, país com tantas diferenças entre suas várias regióes e mesmo dentro delas. Sucessivas reformas vêm procurando melhorar a formação do professor, a partir do reconhecimento de seu papel-chave, mas o cenário continua pouco animador. Dentro dele se destaca a parte que cabe ao estágio supervisionado, como elemento de ligação entre a formação oferecida pela instituição de ensino superior (IES), e a que corresponde à escola. Ambas as instituiçôes têm importante responsabilidade no processo de formação do futuro professor e do estágio é esperado que mantenha o equilíbrio necessário entre elas, para assegurar o desenvolvimento do docente como profissional.

Sáo inúmeros os problemas envolvidos no estágio no Brasil, como tem sido assinalado pela literatura a seu respeito, na qual se destaca a produção de Pimenta (2000), sendo também objeto de estudo de um dos autores deste texto (LÜDKE, 2013; 2015a; LÜDKE \& BOING, 2004). Em sua história, a formação e a ocupação de professores transitaram desde a fase inicial do Brasil Colônia com forte ligação com as instituições religiosas, passando depois para o domínio do Estado, caminhando para o que se pode entender como sua profissionalização, ainda que sem atingir o pleno desenvolvimento dessa etapa, como analisa de modo um tanto radical Maurice Tardif (2013). Concordamos em parte com sua análise, considerando que esse desenvolvimento, embora não seja total, tem trazido benefícios para o fortalecimento da carreira do professor e para a retomada de seu prestígio, ao lado de outras profissóes (LÜDKE, 2014; 2015b). A questão da profissão e da profissionalidade de docentes tem sido alvo da atenção de estudiosos da formaçáo de professores, partindo, em geral, da perspectiva desenvolvida por sociólogos interessados sobre o tema da profissão (DUBAR, 1997). No caso dos professores, ela se reveste de características muito especiais, tornando difícil a aplicaçấo direta do conceito de profissão, tal como se faz em relação às profissóes liberais, mais consolidadas, como a medicina ou a advocacia, das quais se originou o conceito corrente (LÜDKE \& BOING, 2004; LÜDKE, 2015a).

Em paralelo ao desenvolvimento profissional do professor se encontra sua relação com a pesquisa, em sua formação e em seu trabalho. A pesquisa cons- 
titui elemento indispensável ao desempenho autônomo que caracteriza o profissional. Entretanto, poucos recursos em termos de tempo e espaço nas instituiçóes de trabalho e de formação do professor; estímulos e financiamento, em geral, muito escassos; e a pressão cada vez maior sobre as tarefas atribuídas ao profissional docente reduzem consideravelmente a possibilidade de desenvolvimento de atividades ligadas à pesquisa (LÜDKE, 2011a; 2014). O que não reduz a importância de sua presença, nas diferentes perspectivas assinaladas por Beillerot como consumidor ou contribuidor à pesquisa, como participante de um trabalho de pesquisa ou como pesquisador efetivo, responsável por um estudo. Em qualquer dessas situaçôes, insiste o autor, a relação com a investigação e o que ela representa têm o mesmo valor. Há um continuum conectando essas diferentes situações na construção de conhecimentos, função precípua da pesquisa (BEILLEROT, 2001).

Um dos autores deste texto teve oportunidade, recentemente, de desenvolver um estudo junto a uma das principais instituiçóes dedicadas à formação de professores da atualidade, o Instituto de Educação da University College of London (IoE/UCL). Seu grande prestígio, em termos de pesquisas, publicaçôes e formação de profissionais na área da educação, atrai jovens de muitos países em busca de formação de excelência nessa área, bem como pesquisadores, na troca de ideias e de experiências de pesquisa, em busca de sugestôes sobre os muitos problemas que pesam sobre a área da educação e da formação de seus profissionais em todo o mundo hoje.

A acolhida pelo professor que assumiu a parceria com a colega brasileira no IoE foi decisiva para o desenvolvimento do estudo proposto, focado justamente sobre a formação de professores, tema de interesse comum, há muito tempo, aos dois novos parceiros. Este texto é um primeiro fruto dessa parceria, analisando em uma perspectiva dupla, brasileira e inglesa, um velho problema que aflige a formação de futuros professores, não apenas nos dois países envolvidos no estudo. Trata-se do grande desafio de combinar o componente teórico e o prático na preparação de jovens que escolheram o caminho do magistério. O estágio supervisionado se situa em posição central nessa questão.

Como o estágio supervisionado e seus problemas são temas muito conhecidos entre estudiosos do campo da educação no Brasil, decidimos trazer, na primeira seção, a seguir, constataçôes de nossas pesquisas recentes, que procuram avançar sobre aspectos ainda não devidamente considerados, dentro do quadro geral de discussão sobre o tema. A situação da formação de professores na Inglaterra, no que se refere ao problema em foco, será objeto de uma segunda seçáo, fornecendo elementos para esclarecer a complexidade, hoje, reinante entre as várias vias de acesso à profissão docente, resultado de uma longa evolução no sistema de formação inicial de professores, ao longo da história recente do país. Em uma terceira seção são reunidos pontos de chegada a partir do diálogo entre os dois autores e com outros pesquisadores do campo. Não se trata de um estudo da área da 
Educação Comparada ou da História da Educação. Trata-se de uma tentativa de compreender como vem sendo enfrentado o desafio de articular formação teórica e prática na preparaçáo de futuros professores, a partir da visáo em conjunto de dois pesquisadores de países diferentes.

\section{Nossas pesquisas sobre o estágio supervisionado}

Ao final de 2007, a Fundação de Amparo à Pesquisa do Estado do Rio de Janeiro (FAPERJ) lançou uma chamada para financiamento de pesquisas em educação, que procurassem aproximar pesquisadores da universidade e professores das escolas da educação básica da rede pública. Estimulada por constataçôes de dissertaçóes orientadas anteriormente (CARDOZO, 2003; ALBUQUERQUE, 2007), e impressionada pela gravidade dos problemas que cercavam (e ainda cercam) o estágio, a autora brasileira decidiu investigar de perto como ele transcorria de fato. Apresentou um projeto à FAPERJ e compôs uma equipe com dois professores de licenciatura e seus estagiários. A ideia de aproximação entre professores da universidade e da escola, na realização de pesquisas, constitui velho sonho de estudiosos da formação de professores, inspirados em trabalhos de pioneiros, como Stenhouse (1975) e Elliott (1989).

Alguns dos desafios habitualmente enfrentados nesse tipo de investigação foram vencidos neste estudo, a despeito das modestas condiçóes disponíveis: a confiança entre os dois grupos de participantes foi logo estabelecida, permitindo o desenvolvimento dos trabalhos do estágio, entre os estagiários e os professores regentes da escola. Introduzindo-os em todas as dependências do estabelecimento, inclusive na sala dos professores e ao lado dos professores, na regência de aulas e no planejamento da programação do curso, como foi registrado pelos estagiários como aspecto muito positivo desse seu estágio. Esses são alguns dos pontos positivos alcançados pela pesquisa, entre outros reunidos no seu relatório final de 2008 e apresentados em um encontro internacional realizado na universidade, em mesas compostas pelos participantes da pesquisa.

Esta pesquisa constitui um exemplo concreto de trabalho de pesquisa realizado em comum por professores de uma universidade e de uma escola de educação básica da rede pública. O foco no estágio supervisionado, um dos pontos frágeis do processo de formação inicial de professores, acrescenta um ganho na busca de caminhos que levem à superação de suas fragilidades, mesmo dentro das condiçóes limitadas de sua estruturação atual. Foi o ponto de partida para uma série de pesquisas, procurando conhecer mais de perto como está se realizando essa etapa tão importante para a formação de professores.

O tempo de duração para o estágio, consideravelmente aumentado recentemente, não significa garantia de melhor proveito do trabalho dos estudantes, 
em termos de sua efetiva formação pela prática docente. Há uma limitação ao redor desse trabalho, considerando-o praticamente reduzido às atividades de observaçáo do que se passa nas salas de aula. Nem todas as universidades asseguram a carga horária necessária para o trabalho do professor orientador em visita às escolas para verificar o desenvolvimento dos estagiários. De modo especial na rede privada e ainda menos nas instituiçôes não universitárias. Fica, assim, a ação formadora do professor orientador por meio do estágio bastante prejudicada.

O estudante, sujeito central do processo, ocupa, em geral, posição passiva, recebendo prescriçóes que delimitam sua trajetória por meio do curso, cumprindo horários e preenchendo formulários, culminando com a redação de um relatório final, que não terá possibilidade de prestar contribuição para a melhoria dessa fase, já que é entregue após seu término. Essas e outras questóes ligadas ao estágio foram objeto de estudo, estimulado pelos resultados obtidos pela pesquisa de 2008. Procuramos aprofundar, na pesquisa (LÜDKE \& BOING, 2012), análises já elaboradas sobre aspectos reconhecidos pela literatura pertinente como problemáticos e estimulamos sobre eles pesquisas de nossos orientandos.

O primeiro aspecto a receber um estudo especial em uma dissertação de mestrado foi o professor orientador de estagiários na universidade (PIRES, 2011), desenvolvido em uma instituição federal, cobrindo todas as licenciaturas nela desenvolvidas. Entre as várias questóes levantadas pelos professores para explicar a pouca efetividade em sua atuação com os estagiários, ressaltou-se a falta de uma preparação específica para esse trabalho e a falta de um lugar claro atribuído ao professor orientador dentro do curso de formação.

A comparação com a introdução à prática profissional aos estudantes em formação na área da saúde tem nos revelado vários ensinamentos sobre nossas próprias limitações no que tange à formação de futuros professores. Um estudo feito por Guedes (2011), em sua dissertação voltada para a preparação do futuro odontólogo, deixou clara a importância conferida pelos preceptores ao acompanhamento do estudante na introdução à prática odontológica. Eles deixaram claro para a pesquisadora que têm em foco o desempenho de cada estudante e não consideram concluído seu trabalho enquanto não constatarem, em cada um deles, o domínio, na prática, do que é essencial em cada uma das clínicas básicas. "Será usado o período de tempo necessário para que isso seja demonstrado", como respondeu um dos preceptores à pergunta da mestranda sobre qual era o tempo dedicado a essa tarefa.

Em outra dissertação, agora na formação do futuro enfermeiro, Bicalho (2013) mostra mais um interessante aspecto a ser considerado. A introdução do aprendiz de enfermeiro aos trabalhos práticos é feita sob a coordenação de um preceptor responsável, mas com a colaboração de um grupo de assistentes, que dividem com ele a responsabilidade e também as tarefas específicas de cada setor. Tal como acontece com a atençấo do preceptor no curso de Odontologia, 
em sua fase prática ou com a preparação do futuro médico em seu período de internato, diretamente ligado aos preceptores de cada uma das clínicas de formação básica.

Uma das lições centrais desses estudos na área da saúde é a equiparação da qualificação, das condiçôes de trabalho, dos recursos e da consideração profissional, entre os professores encarregados do trabalho formativo na universidade e no domínio da prática nos hospitais e clínicas. O que não ocorre com os responsáveis correspondentes na formação de futuros professores.

Bambino (2012) estudou um dos mais graves problemas do estágio supervisionado no Brasil, a articulação entre as duas instituições responsáveis pela formação de professores: a universidade e a Secretaria de Educação, por meio das escolas a ela subordinadas. Enquanto a universidade procura encontrar saídas para os muitos problemas apontados pelos estudiosos do tema, a Secretaria parece distante dessas dificuldades, voltando-se mais para questóes da ocupação docente. Há pouca atenção voltada especificamente à parte que cabe às escolas e, portanto, à Secretaria, no trabalho de formaçáo. Uma série de itens não tem sido levada em conta na interlocução entre as duas instituições formadoras, como analisou Bambino (2012). Várias iniciativas poderiam facilitar o diálogo entre os dois grupos de professores, os da universidade com mais tempo para se aproximarem dos colegas formadores nas escolas. Estes, com melhores condições de trabalho e mais esclarecimento, preparação e reconhecimento de seu papel como coformadores do futuro professor (ALBUQUERQUE, 2007).

Em uma segunda investigaçáo (2017) procuramos centrar o foco na percepção dos principais protagonistas do estágio sobre seus problemas. Priorizamos a visão do professor orientador na universidade, do professor supervisor nas escolas e, de modo especial, do sujeito central do processo educativo, o estagiário. Todos, a partir da sua vivência, nos ajudaram a perceber como conseguem levar adiante seu trabalho, a despeito das limitaçóes bem conhecidas a respeito do estágio.

$\mathrm{Na}$ nova investigaçáo procuramos atenuar a passividade dos estagiários nas licenciaturas, tão diferente do que se passa com os estudantes na área da saúde, pela parceria com uma escola e o desenvolvimento de algumas atividades por parte dos estagiários, além da apresentaçáo de uma aula-prova, ao final do estágio. Outra iniciativa feliz foi a elaboração, pelos estagiários, de relatórios parciais durante o estágio, com a grande vantagem de fornecer informaçóes para sua melhoria enquanto ocorre.

Temos, assim, um quadro composto por traços que caracterizam o estágio supervisionado no Brasil, tal como vem sendo apresentado por estudiosos do tema, acrescido de constataçóes sobre aspectos ainda pouco considerados, trazidos pelas nossas pesquisas e as de nossas orientandas, agora com a oportunidade de contato com outra realidade, a da formação de professores na Inglaterra, com suas 
semelhanças e diferenças e as muitas reflexóes que poderão provocar sobre a realidade brasileira, a partir de experiências concretamente vividas.

\section{Novas formas de formação de professores na Inglaterra}

$\mathrm{Na}$ época atual, a formação docente se tornou mais centrada nas escolas, ficando o status e a autonomia das IES (em inglês Higher Education Institutions - HEIs) enfraquecidos no processo de formação dos professores. $\mathrm{O}$ intuito de Kenneth Clarke, Secretário de Estado para Educação, de ver os "estudantes [de docência] realmente entrando em uma classe por muito mais tempo durante sua formação" (CLARKE, 1991) acabou se realizando. Conforme a Circular $\mathrm{n}^{\mathrm{o}}$ 9/1992, os estudantes deviam passar pelo menos dois terços de seu tempo em escolas secundárias que, em lugar das HEIs, agora tinham de oferecer noçôes de formação na metodologia de ensino específica da disciplina. Além disso, todas as escolas, tanto as subsidiadas quanto as independentes, podiam se inscrever como parceiras no mercado educacional de formação inicial, em paralelo às HEIs, assumindo "uma responsabilidade protagonista na formação de estudantes de docência para ensinar as matérias em que se especializaram, avaliar alunos e gerenciar aulas; e na supervisão e avaliação de suas competências nestes aspectos" (INGLATERRA, 1992).

Durante o final da década de 1980, os tradicionais cursos de quatro anos de graduação e um ano de pós-graduação foram complementados por novos caminhos para o status de professor qualificado. Aos cursos Bacharelado em Educação (BEd), de quatro anos, ou Bacharelado em Artes/Bacharelado em Ciência (Ba/BSc) com seu Status de Professor Qualificado (QTS), somaram-se programas encurtados de dois e três anos em nível de graduação. Os tradicionais cursos de Certificado de Pós-graduação em Educação (PGCE) de um ano foram complementados por vários caminhos para a obtenção de um PGCE, tais como os de meio período ou o Esquema de Treinamento Docente (ATS). Além desses, foi também introduzido, para não graduados, o Esquema de Habilitação Docente (LTS).

O governo de então estava preocupado em atrair novos contingentes para a docência, e o fez por meio da introdução de uma série de novos caminhos para o ingresso na profissão. Muitos desses novos caminhos estavam relacionados a disciplinas com escassez de professores. Esses caminhos estavam alinhados às intençōes estratégicas do governo, na medida em que contribuíam para a mercantilização da formação docente, ao acentuar a noção de escolha e diversidade, e se opunham aos modelos convencionais de formação docente e à autonomia das HEIs que os ofereciam, incentivando a formaçáo docente centrada nas escolas.

As estratégias do governo se refletiram no estabelecimento de um novo organismo de inspeção. A Lei da Educação (Escolas), de 1992, criou um novo 
departamento náo ministerial de governo, o Departamento do Inspetor-Chefe de Sua Majestade para Escolas, responsável por gerenciar e regular um sistema nacional de inspeção escolar realizada por inspetores independentes na Inglaterra. O novo departamento foi chamado de Departamento de Padróes em Educaçáo (Ofsted). Ele englobava o antigo Inspetor-Chefe de Sua Majestade (HMCI) e seus funcionários, e começou a operar com a aspiração de promover "melhorias por meio de inspeçóes".

O Governo Conservador de 1992 a 1997 adotou duas importantes medidas políticas, que tiveram continuidade nos subsequentes governos do novo trabalhismo. A primeira foi a introdução de esquemas de Formação Inicial de Professores Centrada nas Escolas (SCITT), que também incluía disposiçôes para incentivar consórcios de escolas a oferecer cursos em nível de pós-graduação. Esses consórcios eram grupos de escolas que recebiam verbas diretamente do governo e podiam utilizar o dinheiro da forma que achassem melhor. O esquema permitia às escolas oferecer cursos de formação inicial sem ligação com as HEIs.

A outra iniciativa política foi a proposta de introduçáo do Programa para Professores Graduados (GTP). Ele foi concebido para oferecer um caminho de alta qualidade e com eficiência de custos para o ingresso na profissão docente a indivíduos com graduação adequada que não quisessem seguir um caminho pré-ensino tradicional, mas "prefeririam um caminho de formação feito sob medida, combinado com um emprego de professor". Foi concebido também para atender às necessidades das escolas "que desejarem estar diretamente envolvidas na formação de seus próprios professores”, sem desenvolver um esquema SCITT (INGLATERRA, 1996, p. 1).

Desde o início da estratégia de modernização, o governo do novo trabalhismo de 1997 se envolveu na reformulação da ideia de profissionalismo docente para responder aos desafios da globalização. Em seu prefácio a Excellence in Schools, David Blunkett exigia que a docência fosse uma profissão de "atitude positiva”. Outro passo foi dado no Green Paper, publicado em dezembro de 1997. Nesse documento, o governo apresentava sua intenção de modernizar a mão de obra docente com o desenvolvimento do que chamava de "novo profissionalismo", o qual se traduzia nos requisitos necessários aos professores em uma docência moderna (INGLATERRA, 1998, p. 14). Essa corrente política do novo profissionalismo pode ser entendida como a conclusão de uma mudança de 30 anos, do "profissionalismo individualizado" para novas formas de "profissionalismo gerenciado" e "organizado em rede", aceitando que as "decisóes sobre o que ensinar e como ensinar, e como avaliar as crianças, são tomadas no nível das escolas e em nível nacional, e não pelos próprios professores individuais" (FURLONG, 2005, p. 120). Para alguns, isso sinalizava uma mudança em direção a uma diminuição do status da carreira docente. 
Eliot Freidson (2001) sugeriu que uma profissão é caracterizada por um corpo especializado de conhecimentos e habilidades, uma forma de conferir reconhecimento a esse corpo de conhecimentos, geralmente por uma universidade ou instituição de ensino superior, e um grau de independência do governo, que permite que ela determine por si mesma qual é esse corpo de conhecimentos, bem como os ambientes de aprendizado nos quais os practitioners o adquirem (ETZIONI, 1969; SAKS, 1995). Essa independência do estado tem sido descrita como seu mandato profissional, e diz respeito ao grau ou quantidade de liberdade do controle estatal que a profissão negociou com o governo competente (WHITTY, 2001).

Os governos do Reino Unido têm, nos últimos tempos, redefinido seu papel em relação às profissões e, em certas circunstâncias, seu poder se canalizou consideravelmente para favorecer formas de racionalidade técnica às custas de formas especializadas de conhecimento. Por exemplo, os governos do Reino Unido têm realocado verbas governamentais para a formação em exercício, transferindo-as das universidades (pelos Conselhos de Financiamento do Ensino Superior) para agências quase-governamentais, e estabelecido limites rígidos sobre quais tipos de curso podem ser reconhecidos para fins de desenvolvimento profissional. Isso obscurece a distinção entre especialização discricionária e especialização mecânica, entendidas como trabalho organizado, no primeiro caso, para aumentar, e, no segundo, para limitar o grau de discricionariedade apropriada para que a tarefa seja realizada com sucesso, e constitui um passo em direção à desprofissionalização.

Assim como os governos conservadores anteriores, o governo do novo trabalhismo queria manter um mercado competitivo no campo da formaçáo docente. Em particular, e de grande importância em termos de formação inicial, foram apresentadas sete propostas pelo governo:

- Novos exames nacionais para todos os professores estagiários, para garantir habilidades de alto nível no domínio dos números, das letras e da Tecnologia da Informação e Comunicação (TIC);

- Novas disposiçóes pré-curso para professores estagiários;

- Revisão dos procedimentos para o status de professor qualificado;

- Uma rede de escolas para lançar práticas inovadoras na formação docente conduzida por escolas;

- Cursos mais flexíveis para a formação inicial de professores;

- Incentivo a caminhos baseados em emprego para o ingresso na profissão; e

- Um novo esquema nacional acelerado para recrutar entre os melhores formandos e fazer com que professores de destaque avancem rapidamente na profissão (INGLATERRA, 1998, p. 43). 
Desde quando o PGCE se tornou o principal caminho de ingresso na profissão, em 1980, sua posição foi progressivamente mantida e fortalecida. O número de indivíduos que concluíram cursos BEd diminuiu de 9.530, em 1994, para 5.900, em 2007. Em contraste, o número dos que concluíram o PGCE aumentou de 16.110 para 21.080 no mesmo período. Após o período piloto de 1993 a 1994, o número de ingressantes nos esquemas SCITT aumentou de forma estável, com o ativo suporte da Agência de Formação de Professores (TTA). Inicialmente, os esquemas SCITT eram cursos de PGCE para formação de professores de ensino médio, e depois tornaram-se cursos de formação tanto para professores de ensino médio quanto de ensino fundamental.

De um ponto de vista prático, o que se deve notar é que, com a introdução dos esquemas SCITT, as escolas emergiram como novos locais de formação de professores, competindo com as fontes convencionais de formação de docentes. Atualmente, as escolas são fortemente incentivadas a se envolver integralmente em todos os aspectos da formação inicial de professores. Esse envolvimento pode assumir uma entre três formas: por meio de uma parceria com uma instituição de ensino superior ou universidade reconhecida pela Agência de Desenvolvimento de Formação para Escolas (TDA); por meio do estabelecimento de um consórcio SCITT, no qual um grupo de escolas é reconhecido pela TDA para oferecer formação; ou com a contratação de um funcionário não qualificado, o qual é formado por meio de um programa baseado em emprego. $\mathrm{Na}$ verdade, as escolas são agentes institucionais essenciais na promoção desses novos caminhos de ingresso na profissão.

O que impressiona em meio ao número de mudanças na política de formação docente sob os governos do novo trabalhismo, de 1997 a 2010, é o rápido crescimento de caminhos de ingresso baseados em emprego (EBRs). Em outubro de 2000, a TTA introduziu o caminho de "PGCE flexível" para o status de professor qualificado, na forma de uma série de medidas para aumentar a oferta de professores. Outros caminhos flexíveis introduzidos foram os esquemas denominados fast track e teach first. Esses dois novos esquemas são diferentes, mas estão alinhados a uma estratégia de padrôes e responsabilização, na medida em que são claramente focados em atrair para a profissão indivíduos formados altamente capacitados. O fast track é um programa acelerado de lideranças, estabelecido em 2000 pelo Departamento de Educação e Ciência. Originalmente, visava a atrair e reter uma pequena coorte de formados muito capacitados e indivíduos em mudança de carreira, por meio da oferta de uma trajetória de carreira de status elevado.

O teach first (TF) é uma iniciativa com base em emprego, concebida para recrutar formados com capacitação excepcionalmente alta que se comprometem a ensinar durante dois anos em escolas de ensino médio desafiadoras. Esse esquema está alinhado com a nova estratégia de parcerias, na medida em que a 
sua introdução foi conduzida por duas associaçóes empresariais, a London First e a Bunisness in the Community. Esse esquema é mais uma mudança na responsabilidade pela formação docente desde a introdução do SCITT, com empresas ativamente intervindo na formação inicial de professores. Além disso, seu desenvolvimento foi inspirado em um esquema americano altamente bem-sucedido, o Teach for America (TFA); tanto que o TF partilha semelhanças consideráveis com o esquema TFA (TEACH FIRST, 2009).

\section{Contato entre duas realidades}

Um dos traços de flagrante diferença entre os dois sistemas é a estruturação do curso básico para a formação de professores, no Brasil denominado Licenciatura, se desenvolvendo, em geral, em quatro anos, dedicados inteiramente àquela formaçáo. $\mathrm{Na}$ Inglaterra, o curso que atende à grande maioria de estudantes a caminho do magistério, o PGCE, se desenvolve em um ano letivo, cursado após a conclusão do bacharelado nas diferentes disciplinas. Seria como o sistema que havia no Brasil, conhecido como 3+1. Temos, assim, a oportunidade de analisar possíveis efeitos sobre os dois sistemas, dentro de estruturaçóes diferentes. A formação intensa, concentrada no curso oferecido pelo PGCE, procura assegurar em um ano a introdução às disciplinas consideradas indispensáveis à formação do futuro professor, em complementação à formação recebida por cada estudante, em sua disciplina central no curso de bacharelado.

O PGCE procura integrar, durante esse trabalho concentrado em um ano letivo, a formação anterior com a nova, dedicada à área pedagógica, trabalhando com as disciplinas próprias dessa área, em conexâo com as disciplinas próprias ao ensino das áreas específicas. Para o ponto a ressaltar aqui queremos destacar que toda a preparação do estudante como futuro docente se concentra no quarto ano, inclusive a relativa ao conteúdo específico, o que aponta para a grande questão da formaçáo do profissional do magistério, com o peso próprio de cada um dos componentes curriculares, incluindo o que corresponde à prática.

O trabalho desenvolvido nas escolas, no sistema inglês, dedicado à preparação prática do futuro professor, corresponde ao estágio supervisionado, no sistema brasileiro, foco específico deste texto. O que nossas pesquisas têm demonstrado e tem sido confirmado pela vasta literatura dedicada ao tema é a precariedade com que esse trabalho, voltado ao lado prático, tem sido realizado no Brasil. Os traços gerais apontados, rapidamente, nos permitem perceber diferenças estruturais entre as duas realidades estudadas, com consequências diretas sobre o estágio.

A organização do trabalho do PGCE nas escolas associadas à universidade, na Inglaterra, com muita atenção aos seus professores, os mentores, desponta como ponto muito positivo, indo ao encontro do que pode contribuir para a me- 
lhoria do estágio supervisionado no Brasil. Já o tempo de duração do curso destinado à formação docente, de um ano letivo, com todas as disciplinas importantes para essa formaçáo e todos os trabalhos desenvolvidos em ritmo intenso, que absorve "24 horas por dia", no dizer de estudantes entrevistados, parece concentrado em demasia. Ainda mais ao considerarmos que ele envolve o período de prática nas escolas, que toma a maior parte do tempo total do curso.

Aqui entra outro ponto, ligado a um aspecto central da grande questáo da formação de professores, que envolve a relação entre teoria e prática e seu equilíbrio nessa formação. Nas várias entrevistas com professores, das diferentes categorias do IoE, esse tema aflorou, sobretudo, na voz de professores mais vividos, que experimentaram outra realidade quanto à formaçáo de professores, e, como alguns chegaram a expressar, hoje aparece como um recuo da formação teórica. Essa orientação crescente no sistema inglês de clara predominância da vertente da prática na formaçáo de futuros professores, como apontou Lawes em sua tese de doutorado, pode representar The End of Theory? (LAWES, 2004). Em entrevista recente a autora confirmou sua percepção de que as coisas só pioraram desde então.

Em artigo de 1990, Young já prenunciava o abatimento da preparação teórica feita pela universidade e anunciava uma verdadeira crise na formação de professores por ela oferecida. Entretanto, alertava que a falsa polarização entre teoria e prática leva a uma visão do ensino bastante limitada, como atividade essencialmente prática, baseada em "habilidades" e "competências", que podem ser adquiridas junto a um educador experiente. E se perguntava, então, se não seria possível resgatar da velha tradição algum recurso, não inteiramente contaminado pelo seu elitismo, que possa compor com novos elementos uma base alternativa ante o atual pragmatismo dos estudos educacionais. Essas ideias de Young, escritas há mais de 20 anos, têm uma incrível atualidade.

Uma contribuição recente de Claude Lessard e Anylène Carpentier pode nos ajudar a ver com olhos mais esperançosos os difíceis caminhos percorridos na formação de estudantes em busca do magistério, tanto no Brasil como na Inglaterra. Lessard e Carpentier discorrem sobre a importância e as dificuldades do trabalho nesse campo, em um livro que anuncia seu muito oportuno objetivo logo no título Politiques éducatives: la mise en oeuvre (LESSARD \& CARPENTIER, 2015). Náo se trata da aplicaçáo de alguma coisa decidida do alto do sistema, mas do produto de uma resposta do meio e da base da pirâmide, a uma pressáo para a mudança vinda do alto e da própria sociedade, passando pelo debate e pela controvérsia.

Tanto na Inglaterra como no Brasil, a educação tem sofrido com as injunçóes de uma sucessão de reformas, introduzidas por políticas que se sucedem, resultando na complexa situação atual indicada na Inglaterra e bem conhecida no Brasil. Lessard e Carpentier (2015) trazem, a propósito, uma contribuiçáo de Schön, em parceria com Rein, em obra pouco conhecida de 1994. Esses autores 
propõem uma posição alternativa, entrando com o que chamam de um "diálogo informado". Muitas vezes o diálogo toma a forma de um desacordo ou de uma controvérsia. Um desacordo sobre os fatos é bem mais fácil de ser superado do que uma controvérsia sobre os valores, dizem os autores, trazidos por Lessard e Carpentier (2015).

O diálogo informado entre os diferentes atores do campo político pode ser um importante auxiliar na condução dos conflitos no interior e entre os vários quadros de referências (frames) envolvidos, permitindo, eventualmente, sua hibridização ou mestiçagem, segundo Lessard e Carpientier, que afirmam: "A via proposta por Schön e Rein leva ao estudo dos usos da pesquisa pelos atores, sejam eles situados no alto da pirâmide educativa ou atores da produção local do serviço educativo" (LESSARD \& CARPIENTIER, 2015, p. 185-186). Ao apresentar as políticas públicas fora de uma visão linear centrada no Estado, mas em uma perspectiva de construção de uma ação pública de múltiplos atores, agindo em diferentes níveis, em um movimento gradual de mudança e aprendizagem, Lessard e Carpentier (2015, p. 190) estimulam-nos a situar o papel da pesquisa e do pesquisador em posição central na cena política, assegurando a nutrição do diálogo informado, entre os atores envolvidos.

Tanto nas afirmaçóes dos autores consultados, como nas dos professores do IoE, fica assinalado o lugar da universidade no que se refere à preparação do componente teórico na formação do futuro professor. Essa questáo constitui motivo de preocupação para muitos deles, após a passagem da responsabilidade efetiva dos cursos, em grande parte, para o trabalho nas escolas. Toda a complexa tarefa de levar o estudante pelos caminhos de seu amadurecimento teórico, indispensável para sua formaçấo como profissional, hoje, com a maior parte do tempo do curso entregue à escola, parece uma tarefa impossível, como chegaram a dizer alguns dos entrevistados.

Indissoluvelmente ligado ao componente teórico se encontra o papel da pesquisa, indispensável na preparação de todo profissional. No caso do professor ele aparece de modo evidente, pela sua atuação em um tipo de trabalho que exige decisōes e adaptaçóes constantes, ante as necessidades dos seus alunos, como ocorre com os médicos e seus pacientes. Entretanto, a formação dos futuros médicos prevê o contato com a pesquisa e sua importância para todos os profissionais da medicina, o que não ocorre entre os professores.

A experiência vivida pelo esforço do pessoal envolvido no curso do PGCE no IoE procura conciliar vários dos fatores de grande influência sobre a formação de professores, que discutimos ao longo deste texto. Ela poderá oferecer importante contribuição para a discussão da questão título deste artigo.

Em uma primeira visão conjunta, a partir das análises sobre a situação da formação de professores em dois países, no que toca à articulação entre o aspecto teórico e o prático, podemos adiantar que o lugar do estágio se encontra em po- 
sição questionável em ambas as realidades. De um lado, no Brasil, há um período muito reduzido dedicado explicitamente ao contato direto com a prática docente, hoje representando cerca de $25 \%$ do tempo dedicado ao curso de licenciatura. Do lado inglês, na via mais frequente seguida pelos candidatos ao magistério, o PGCE, esse período ocupa perto de $80 \%$.

A rápida apresentação das duas realidades que trouxemos não permitirá conhecer inteiramente como cada uma se apresenta de fato, mas é suficiente para deixar clara a disparidade entre elas na preparação prática do futuro professor. No Brasil, essa preparação, além de ocupar uma porção bem mais modesta do curso no estágio, sofre uma série de percalços, que a tornam muito pouco efetiva. $\mathrm{Na}$ Inglaterra, esse período representa a parte central do curso, restando uma porçáo bem modesta para o trabalho de formação teórica a cargo da universidade, enquanto no Brasil há um desenvolvimento paralelo entre as disciplinas de ambos os setores, o especifico e o pedagógico, ao longo do curso, naquele país, há uma clara distinção entre as duas formaçóes.

Várias questôes ligadas às composiçóes em cada uma das realidades estudadas exigem análises posteriores. Trouxemos traços mais gerais que as caracterizam e permitem vislumbrar importantes consequências sobre a formação de professores. Uma delas, na Inglaterra, acentuadamente centrada na preparação prática realizada nas escolas, corre o risco de oferecer formação insuficiente na fundamentação teórica, indispensável ao profissional do magistério no mundo atual, com todos os desafios a enfrentar. A outra composição, no Brasil, procurando integrar a formação específica e a pedagógica, ao longo do curso desde seu início, carece, entretanto, de melhor cuidado com a formação prática, perante uma articulação hoje muito precária entre a IES e as escolas.

Em meio às várias tensões em torno do campo da educação na busca de sua definição no domínio científico, a formação de professores ocupa espaço basilar e o estágio é braço ativo para o encaminhamento do futuro profissional à formação prática. A aproximação entre duas realidades que concretizam de modo bem diverso esse encaminhamento oferece-nos oportunidade de conhecer implicaçóes dos diferentes esquemas experimentados. Nosso escopo neste texto foi trazer nossa visão sobre essas implicações em direção à urgente contribuição esperada da pesquisa para discussão e reflexão sobre desafios sofridos pela educação e pela formação de professores no cumprimento de seus amplos fins, hoje, tão esmaecidos em favor da "engenharia social que foca sobre o que funciona para o desenvolvimento econômico" (LABAREE, 2017, p. 283). No Brasil e na Inglaterra o estágio tem sua importância bem reconhecida. No lado brasileiro há uma atenção maior às disciplinas de conteúdo específico e da área pedagógica por conta da universidade. $\mathrm{Na}$ Inglaterra elas são atribuídas ao trabalho das escolas, em paralelo às atividades de docência prática. É preciso buscar um equilíbrio entre as duas articulaçôes, o que esperamos seja feito pela pesquisa, aproximando os trabalhos dos professores da universidade e da escola em mútua iluminação. 


\section{Referências}

ALBUQUERQUE, S.B.G. Estágio supervisionado e parceria na formação de professores. Dissertação (Mestrado em Educação) - Pontifícia Universidade Católica do Rio de Janeiro, Rio de Janeiro, 2007.

BAMBINO, V.P. O Estágio supervisionado e as instituiçôes responsáveis em diálogo. Dissertação (Mestrado em Educação) - Universidade Católica de Petrópolis, Petrópolis, 2012.

BEILLEROT, J. A pesquisa: esboço de uma análise. In: ANDRÉ, M. (Org.). O papel da pesquisa na formação e na prática dos professores. Campinas: Papirus, 2001. p. 71-90.

BICALHO, E.A. O estágio supervisionado: entre futuros enfermeiros e futuros professores. Dissertação (Mestrado em Educação) - Universidade Católica de Petrópolis, Petrópolis, 2013.

BLUNKETT, David. White paper: excellence in schools. London, 1997. Disponível em: <http://www.educationengland.org.uk/documents/wp1997/excellence-in-schools.html>. Acesso em: 23 jan. 2018.

CARDOZO, S.A. Universidade e escola: uma via de mão dupla? Dissertação (Mestrado em Educação) - Pontifícia Universidade Católica do Rio de Janeiro, Rio de Janeiro, 2003.

CLARKE, K. Speech to Conservative Party Conference, set. 1991.

DUBAR, C. A socialização: construção das identidades sociais e profissionais. Porto: Porto, 1997.

ELLIOTT, J. Educational theory and the professional learning of teachers: an overview. Cambridge Journal of Education, v. 19, n. 1, p. 81-101, 1989. DOI: $10.1080 / 0305764890190110$

ETZIONI, A. The semi-professions and their organization: teachers, nurses, social workers. Londres: Collier-MacMillan, 1969.

FREIDSON, E. Professionalism: the third logic. Chicago: University of Chicago Press, 2001.

FURLONG, J. New Labour and Teacher Education: the end of an era? Oxford Review of Education v. 31, n. 1, p. 119-134, 2005.

GUEDES, E.A. O estágio supervisionado na formação de futuros profissionais nas áreas da educação e da saúde: o caso da odontologia. Dissertação (Mestrado em Educaçáo) Universidade Católica de Petrópolis, Petropólis, 2011.

INGLATERRA. Departamento de Educação e Ciência. Curriculum organisation and classroom practice in primary schools: a discussion paper. Londres: Departamento de Educação e Ciência, 1992.

- Departamento de Educação e Emprego. Graduate Teacher Programme: consultation paper. Londres: Departamento de Educação e Emprego, 1996.

Departamento de Educação e Emprego. Teaching: high status, high standards: requirements for courses of initial teacher training. Circular 4/98. Londres: Departamento de Educação e Emprego, 1998. 
LABAREE, D.F. Futures of the field of education. In: WHITTY, G.; FURLONG, J. (Eds.). Knowledge and the study of education: an international exploration, studies in comparative education. Londres: Symposium Books, 2017.

LAWES, S. The end of theory? A comparative study of the decline of educational theory and professional knowledge in modern foreign languages teacher training in England and France. Tese (Doutorado em Filosofia) - Instituto de Educação, Universidade de Londres, 2004.

LESSARD, C.; CARPENTIER, A. Politiques éducatives: la mise en oeuvre. Paris: PUF, 2015.

LÜDKE, M. (Ed.). O professor e a pesquisa. 7. ed. Campinas: Papirus, 2011 a.

. Estágio supervisionado: substantivo fictício? In: GATTI, B. et al. (Eds.). Por uma revolução no campo da formação de professores. São Paulo: Editora da Unesp, 2015a. p. 171-185.

O estágio nos cursos de formação de professores como uma via de mão dupla entre universidade e escola. Relatório de pesquisa. Rio de Janeiro: PUC-Rio/FAPERJ, 2008.

. O lugar do estágio na formação de professores. Educação em Perspectiva, Viçosa, v. 4, n. 1, p. 111-133, jan.-jun. 2013. https://doi.org/10.22294/eduper/ppge/ufv.v4i1.410

O papel da pesquisa na formação de professores. In: OLIVEIRA, M.R.N.S. de. Professor: formação, saberes e problemas. Porto: Porto, 2014. v. 7. p. 49-65.

O professor, sua pesquisa e sua "profissão". In: OLIVEIRA, D.A.; FELDFEBER, M.; SOUZA, E.C. (Eds.). Inclusão democrática e direito à educação: desafios para a docência na América Latina. Belo Horizonte: Unika, 2015b. v. 1. p. 171-185.

LÜDKE, M.I.; BOING, L.A. Caminhos da profissão e da profissionalidade docentes. Educação \& Sociedade, Campinas, v. 25, n. 89, p. 1159-1180, set.-dez. 2004. http:// dx.doi.org/10.1590/S0101-73302004000400005

; _ Do trabalho à formação de professores. Cadernos de Pesquisa, v. 42, n. 146, p. 428-451, 2012. http://dx.doi.org/10.1590/S0100-15742012000200007

PIMENTA, S.G. A formação do professor necessário para a escola cidadã. Revista de Educação, Salvador, v. 29, p. 7-18, 2000.

PIRES, F.C.O. O papel do professor orientador na efetiva-ação do estágio: múltiplas visóes. Dissertação (Mestrado em Educação) - Universidade Católica de Petrópolis, Petrópolis, 2011.

SAKS, M. Professions and the public interest: medical power, altruism and alternative medicine. Londres: Routledge, 1995.

SCHÖN, D.A.; REIN, M. Frame reflection: toward the resolution of intractable policy controversies. Nova York: Basic Books, 1994.

STENHOUSE, L. An introduction to curriculum research and development. Londres: Heinemann, 1975. 
TARDIF, M. A profissionalização do ensino passados trinta anos: dois passos para a frente, três para trás. Educação \& Sociedade, Campinas, v. 34, n. 123, p. 551-571, jun. 2013. http://dx.doi.org/10.1590/S0101-73302013000200013

TEACH FIRST, 2009. Disponível em: <https://www.teachfirst.org.uk/our-history >. Acesso em: 23 jan. 2018.

WHITTY, G. Teacher professionalism in new times. In: GLEESON, D.; HUSBANDS, C. (Eds.) The performing school: managing, teaching and learning in a performance culture. Londres e Nova York: Routledge Falmer, 2001.

WHITTY, G.; FURLONG, J. (Eds.). Knowledge and the study of education: an international exploration, studies in comparative education. Londres: Symposium Books, 2017.

YOUNG, M. Bridging the theory/practice divide: an old problem in a new context. Educational and Child Psychology, v. 7, n. 3, 1990.

Recebido em 02 de agosto de 2017.

Aprovado em 30 de novembro de 2017. 